\title{
Versatile hollow fluorescent metal-silica nanohybrids through a modified microemulsion synthesis route
}

Alberto Clemente, ${ }^{,}$Nuria Moreno, ${ }^{2}$ M. Pilar Lobera, ${ }^{12}$ Francisco Balas ${ }^{12^{2}}$ and Jesus Santamaria' ${ }^{12}$

' Instituto de Nanociencia de Aragón (INA), Universidad de Zaragoza, 50018 Zaragoza, Spain

${ }^{2}$ Networking Research Centre for Bioengineering, Biomaterials and Nanomedicine (CIBERBBN), 28040 Madrid, Spain

\section{ABSTRACT}

Silica-metal nanohybrids are common materials for applications in biomedicine, catalysis or sensing. Also, hollow structures are of interest as they provide additional useful features.

However, in these materials the control of the size and accessibility to the inner regions of the structure usually requires complex synthesis procedures. Here we report a simple colloidal procedure for synthesizing hollow silica-metal nanohybrids, driven by the diffusion of metal precursors through the porous silica shell and subsequent reduction in aqueous solutions. The formation of hollow nanoparticles is controlled by the colloidal conditions during synthesis, which affect the ripening of hollow nanoparticles in presence of organosilanes. The modification of the conditions during synthesis affected the growth of silica precursors in presence of fluorescein isothiocyanate (FITC). The limited access to water molecules during the hydrolysis of silica precursors is attributed to the hydrophobicity of organic fluorescent molecules linked to the condensing silica clusters at the initial stages of nanoparticle formation and to the limitation of water content in the microemulsion method used. Finally, the growth of metal nanoseeds at the core of hollow nanoparticles can be easily achieved though a simple method in aqueous environment. The $\mathrm{pH}$ and thermal conditions during the reduction process affect the formation of metal-silica nanohybrids and their structural features.

\section{KEYWORDS}

Silica; Microemulsion; Hollow; Nanoparticles; Fluorescence; Nanohybrids 


\section{INTRODUCTION}

The potential of nanotechnology for transforming the scientific and industrial world along with our everyday life is already a matter of fact $[1,2]$. New fabrication procedures are being investigated for the development of new nanomaterials with numerous applications $[3,4]$. Of especial interest are nanocomposites and nanohybrids $[5,6]$, which show unique properties with applications in catalysis [7,8], medicine [9], sensing [10], energy storage [11] or photonics [12], to cite a few. Furthermore, using specific fluorescent markers, these hybrid nanomaterials have proven their utility as tracers for risk assessment in nanosafety applications [13-15].

The silica-metal nanohybrids combine the chemical activity of metal clusters with a versatile nanoscale silica shell [16-20]. These have been loaded with drug molecules to obtain efficient smart-responsive drug delivery systems [21] or with luminescent moieties to produce light-reactive nanoparticles [22] as well as with superparamagnetic iron oxides to enable magnetic response [16,23]. The extraordinary thermal and chemical stability, high hydrophilicity and biocompatibility of the silica matrix have allowed further applications in other areas [24].

The synthesis of nanohybrids is considered a laborious procedure, difficult to be scaled up and prone to reproducibility problems $[25,26]$. Conventional synthesis methods involve the formation of voids within solid nanoparticles and further incorporation of small metallic clusters into cavities [27] or by means of sacrificial cores enclosed in a solid shell $[28,29]$. Other procedures based in the Ostwald ripening have been also reported to produce core-shell structures in a variety of compositions [30]. For the synthesis of silica nanohybrids, the Stöber method is usually the reference procedure [31,32]. Microemulsion methods have been proposed to produce complete nanoscale shells, which show excellent control in the surface hydroxylation [33]. Yet, the synthesis of functional silica-metal nanohybrids with narrow particle size distributions remains a great challenge [34]. 
Here we report a novel procedure to synthesize fluorescent hollow silica-metal nanohybrids. To this end, monodisperse fluorescent silica nanoparticles were synthesized in a water-in-oil microemulsion and further stabilized in anhydrous ethanol. To shed light on the process of formation of hollow nanostructures, we have tested the influence of several parameters, namely ionic strength, $\mathrm{pH}$, temperature, and reagent concentration. Under the appropriate conditions, fluorescent silica-metal nanohybrids have been obtained by secondary processing of the hollow nanostructures in aqueous solutions of the suitable metal precursors.

\section{EXPERIMENTAL SECTION}

\section{Reagents}

Tetraethyl orthosilicate (TEOS, 98\%, Aldrich, St. Louis MO), 3-aminopropyl ethoxysilane (APTES, 99\%, Aldrich), ethanol (EtOH, 99\%, Aldrich), cyclohexane (99\%, Aldrich), n-hexanol (99\%, Aldrich), polyethylene glycol p-(1,1,3,3-tetramethylbutyl)-phenyl ether (Triton X-100, 99\%, Aldrich), 3-(trihydroxysilyl)propyl methylphosphonate (THPMP, $42 \%$, Aldrich) and benzyl alcohol (BzOH, Aldrich) were used as received. Milli-Q grade water (Millipore, Billerica MA) and ammonium hydroxide $\left(\mathrm{NH}_{4} \mathrm{OH}, 25-28 \%\right.$ solution in water, Aldrich) were used for the hydrolysis of silicate precursors. Fluorescein 6isothiocyanate (FITC, 99\%, Aldrich) was used without previous purification. Gold (III) chloride trihydrate $\left(\mathrm{HAuCl}_{4} \cdot 3 \mathrm{H}_{2} \mathrm{O}, \geq 49.0 \%\right.$ Au basis, Aldrich), hydrogen hexachloroplatinate (IV) hexahydrate $\left(\mathrm{H}_{2} \mathrm{PtCl}_{6} \cdot 6 \mathrm{H}_{2} \mathrm{O}, \geq 37.5 \%\right.$ Pt basis, Aldrich) and silver nitrate $\left(\mathrm{AgNO}_{3}\right.$, Aldrich) were used as metal sources, along with sodium borohydride $\left(\mathrm{NaBH}_{4}\right.$, Aldrich) as reducing reagent.

\section{Synthesis of monodisperse fluorescent metal-silica nanohybrids}

Monodisperse fluorescent silica $\left(\mathrm{F}-\mathrm{SiO}_{2}\right)$ nanoparticles were synthesized by modified single emulsion method at room temperature [35]. Typically, a water-in-oil (w/o) microemulsion was prepared by dissolving a cyclohexane/Triton X-100/n-hexanol/water 
mixture with a molar ratio 25.4/1/4.5/6.7. On the other hand, a fluorescent silicate precursor was synthesized by dissolving $5.7 \mathrm{mg}$ of FITC in $1 \mathrm{ml}$ of ethanol. A volume of $73 \mu \mathrm{l}$ of APTES was added under Ar atmosphere at $25^{\circ} \mathrm{C}$ to the FITC solution and the mixture was stirred in dark during $12 \mathrm{~h}$ to obtain FITC-APTES conjugate where fluorescein was grafted to the organoalkoxysilane through thiourea bonds. Finally, $\mathrm{F}_{-} \mathrm{SiO}_{2}$ nanoparticles were prepared by adding $100 \mu 1$ of the FITC-APTES conjugate to the microemulsion under vigorous stirring, followed by the consecutive addition after $10 \mathrm{~min}$ of $100 \mu \mathrm{l}$ of TEOS and $100 \mu \mathrm{lof} \mathrm{NH}_{4} \mathrm{OH}$. After stirring for $30 \mathrm{~min}, 15 \mu \mathrm{l}$ of THPMP was added and the mixture was kept for $24 \mathrm{~h}$ under stirring in dark at $25^{\circ} \mathrm{C}$. The $\mathrm{F}-\mathrm{SiO}_{2}$ nanoparticles were then precipitated and washed using several cycles of centrifugation $\left(10^{4} \mathrm{rpm}, 10 \mathrm{~min}\right)$, re-suspension in $\mathrm{EtOH}$ and ultrasonic dispersion $\left(80 \mathrm{~W}, 2 \mathrm{~min}\right.$ ) to remove the reagent excess. The $\mathrm{F}-\mathrm{SiO}_{2}$ nanoparticles were finally stabilized in $\mathrm{EtOH}$ and stored for further treatments. Hollow fluorescent $\mathrm{FH}-\mathrm{SiO}_{2}$ nanoparticles were obtained by centrifugation $\left(10^{4} \mathrm{rpm}, 10 \mathrm{~min}\right)$ of $\mathrm{F}_{-} \mathrm{SiO}_{2}$ nanoparticles and re-suspension in Milli-Q deionized water up to a concentration of $1 \mathrm{mg} / \mathrm{ml}$. The $\mathrm{FH}^{\mathrm{S}}-\mathrm{SiO}_{2}$ nanoparticles were then kept in water under dark conditions at $25^{\circ} \mathrm{C}$ for several periods, solution temperatures and $\mathrm{pH}$ conditions to form the inner void.

The ethanol-stabilized $\mathrm{F}-\mathrm{SiO}_{2}$ nanoparticles were eventually re-suspended in 1-mM aqueous solutions of silver, gold and platinum precursors for five days under dark conditions at $25^{\circ} \mathrm{C}$. An excess of $\mathrm{NaBH}_{4}\left(\right.$ molar ratio $4 \mathrm{BH}_{4}^{-} / \mathrm{SiO}_{2}$ ) was subsequently added under vigorous stirring to the suspension. Finally, metal-containing $\mathrm{FH}-\mathrm{SiO}_{2}$ nanohybrids were separated by centrifugation $\left(10^{4} \mathrm{rpm}, 15 \mathrm{~min}\right)$ and the resulting pellet was washed with a $1: 1$ $\mathrm{H}_{2} \mathrm{O} / \mathrm{EtOH}$ solution. This procedure was repeated twice for every $\mathrm{M} @ \mathrm{SiO}_{2}(\mathrm{M}=\mathrm{Ag}, \mathrm{Au}$ and $\mathrm{Pt}$ ) nanohybrid and finally stabilized in EtOH for further analysis. The overall synthesis process that led to hollow fluorescent $\mathrm{SiO}_{2}$ and $\mathrm{M} @ \mathrm{SiO}_{2}$ nanoparticles was schematized in Figure 1. 


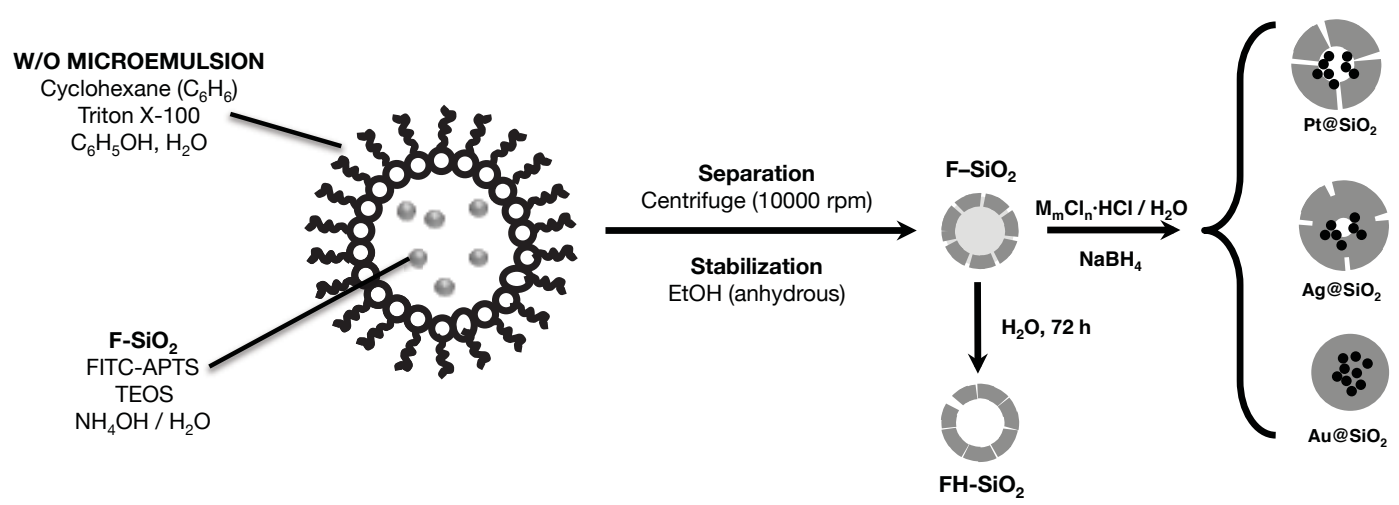

Figure 1. Scheme of the water-in-oil (W/O) microemulsion synthesis of $\mathrm{F}-\mathrm{SiO}_{2}$ nanoparticles and the subsequent synthesis of hollow fluorescent $\mathrm{FH}-\mathrm{SiO}_{2}$ nanoparticles and $\mathrm{M} @ \mathrm{SiO}_{2}$ nanohybrids $(\mathrm{M}=\mathrm{Pt}, \mathrm{Ag}$ and $\mathrm{Au})$

\section{Characterization}

Textural properties were measured by $\mathrm{N}_{2}$ adsorption at $77 \mathrm{~K}$ (TriStar 3000 V6.08, Micromeritics Corp., Noncross, GA). Assuming loosely attached nanoparticle agglomerates with some degree of surface texture [36], the presence of both interparticle and intraparticle mesopores was determined by means of a non-linear density functional theory (NLDFT) model to the $\mathrm{N}_{2}$ adsorption branch of the isotherms (see ESM for details). The morphology of the synthesized nanoparticles was assessed by means of electron microscopy techniques. Transmission electron microscopy (TEM) images were taken in a Tecnai T20 (FEI Co, Hillsboro OR) microscope at a $200 \mathrm{kV}$. Particle size distributions were obtained from statistical analysis of TEM images using the Image-J processing software with a number of measured particles $(\mathrm{N})$ larger than 75 in every image. Scanning transmission electron microscopy (STEM) images were collected in a Tecnai F30 (FEI Co) microscope at $80 \mathrm{kV}$. For Z-contrast imaging of $\mathrm{FH}-\mathrm{SiO}_{2}$ and $\mathrm{M} @ \mathrm{FH}-\mathrm{SiO}_{2}$ nanoparticles, the high angle annular dark field (HAADF) technique was used, consisting in a STEM detector with a large inner radius that avoided the Bragg scattering intensity and ensuring that transmission intensity was roughly proportional to $\left(\mathrm{Z}^{2}\right)$ [37]. Dynamic light scattering (DLS) measurements were performed in a Brookhaven 90Plus (Brookhaven Instruments Inc., New Jersey NJ) to determine the hydrodynamic diameter of the fluorescent hollow silica nanoparticles in water 
suspension. The fluorescence emission of $\mathrm{F}-\mathrm{SiO}_{2}, \mathrm{FH}-\mathrm{SiO}_{2}$ and $\mathrm{M} @ \mathrm{FH}-\mathrm{SiO}_{2}$ nanoparticles was recorded in a Perkin-Elmer LS45 (Perkin-Elmer Inc, Waltham MA) spectrophotometer. The absorption and emission wavelengths were 490 and $516 \mathrm{~nm}$ respectively with a scan speed of $100 \mathrm{~nm} / \mathrm{min}$ and a $7.5 \mathrm{~nm}$ grid monochromator. Ultraviolet and visible spectra (UVvis) were measured in an Agilent 8453 (Agilent Technologies, Santa Clara CA) equipped with $\mathrm{W}$ and $\mathrm{D}_{2}$ lamps for both visible and ultraviolet spectra. The surface metal-to-silicon atomic ratio of the $\mathrm{M} @ \mathrm{FH}-\mathrm{SiO}_{2}$ nanoparticles was analyzed using X-ray photoelectron spectroscopy (XPS) in a Kratos AXIS Ultra DLD (Kratos Analytical, Manchester, UK) system operating with the monochromatic Al Ka beam at $1466 \mathrm{eV}$. Proton nuclear magnetic resonance ('H-NMR) spectra were alternatively recorded using Avance-400 and Avance-500 spectrometers (Bruker Corporation, Billerica MA).

\section{RESULTS AND DISCUSSION}

The synthesis of nanohybrids started from uniform fluorescent silica nanoparticles (F$\mathrm{SiO}_{2}$ ) with an average particle size of $60 \pm 2 \mathrm{~nm}$. These were obtained using in a w/o microemulsion method followed by stabilization in anhydrous ethanol (Figure 2a). This suspension was further processed in deionized water to produce fluorescent hollow nanoparticles $\left(\mathrm{FH}-\mathrm{SiO}_{2}\right)$ with a spherical shape and a narrow particle size distribution (Figure 2b). The immersion of $\mathrm{F}_{-} \mathrm{SiO}_{2}$ nanoparticles in aqueous solutions containing metal ions and subsequent reduction led to the formation of silica-metal nanohybrids with diverse morphologies, from metal-filled $\mathrm{Au} @ \mathrm{SiO}_{2}$ nanoparticles (Figure 2c) to $\mathrm{Ag} @ \mathrm{SiO}_{2}$ and $\mathrm{Pt} @ \mathrm{SiO}_{2}$ nanorattles (Figures $2 \mathrm{~d}$ and e). Average silica nanoparticle size was constant during the process leading to nanohybrids. Interestingly, the process to form $\mathrm{FH}-\mathrm{SiO}_{2}$ nanoparticles only seems to have an effect the inner part of the nanoparticle. The STEM tomography profile (Figure 3) showed that the core of $\mathrm{FH}-\mathrm{SiO}_{2}$ nanoparticles displayed a reduced density that was attributed to the formation of hollow structures that did not affect the shell walls. 


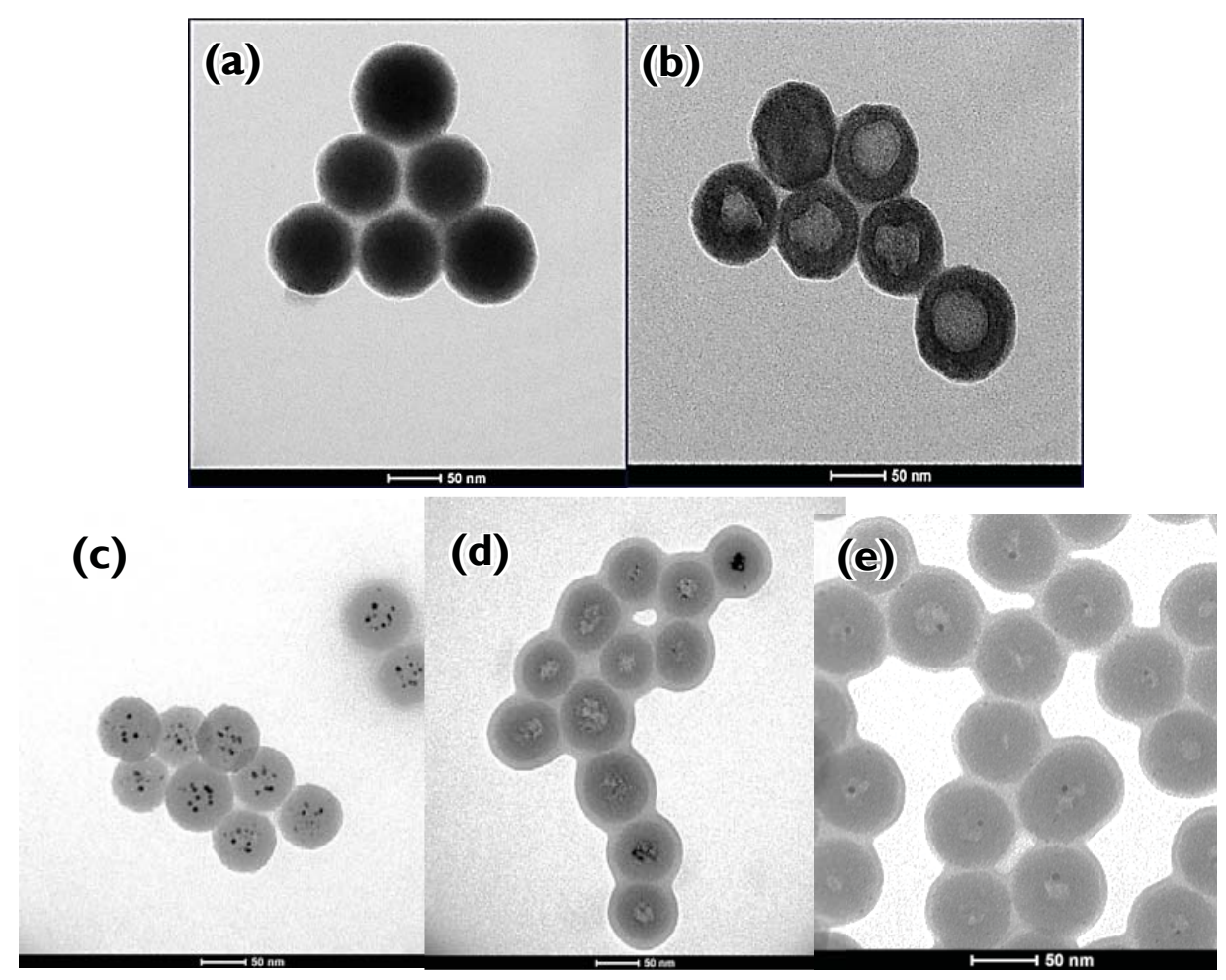

Figure 2. (a) TEM images of (a) the $\mathrm{F}-\mathrm{SiO}_{2}$ upon microemulsion synthesis and stabilization in $\mathrm{EtOH}$, (b) $\mathrm{FH}-\mathrm{SiO}_{2}$ nanoparticles obtained after $5 \mathrm{~d}$ in water at $25^{\circ} \mathrm{C}$; (c) $\mathrm{Au} @ \mathrm{SiO}_{2}$, (d) $\mathrm{Ag} @ \mathrm{SiO}_{2}$ and (e) $\mathrm{Pt} @ \mathrm{SiO}_{2}$ nanohybrids obtained by immersion of $\mathrm{F}-\mathrm{SiO}_{2}$ in 1-mM aqueous solutions of $\mathrm{AgNO}_{3}, \mathrm{HAuCl}_{4}$ and $\mathrm{H}_{2} \mathrm{PtCl}_{6}$ at $25^{\circ} \mathrm{C}$ for $5 \mathrm{~d}$ in dark and subsequent reduction with $\mathrm{NaBH}_{4}$ at $25^{\circ} \mathrm{C}$.
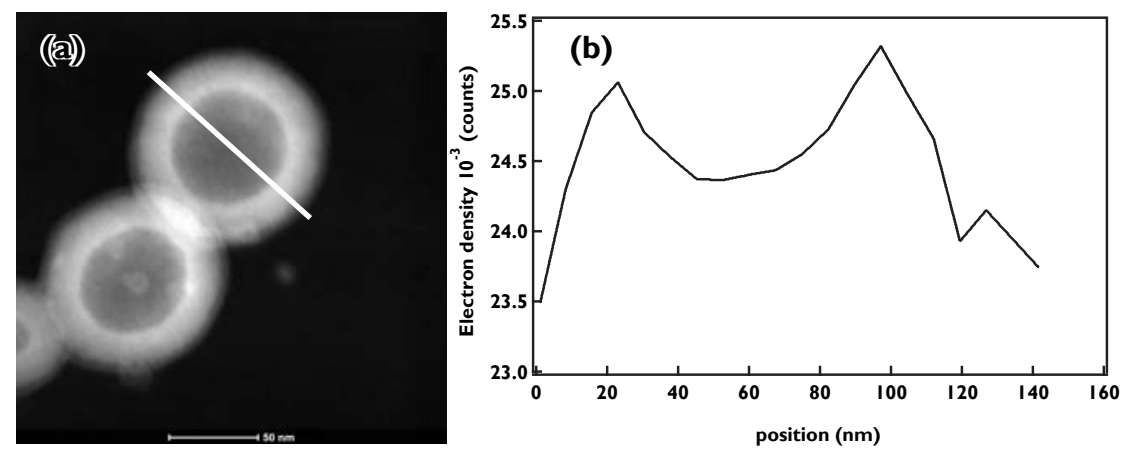

Figure 3. High-angle annular dark field (HAADF) STEM tomography image (a) and electron density profile (b) of a typical $\mathrm{FH}-\mathrm{SiO}_{2}$ nanoparticle obtained after water aging for $5 \mathrm{~d}$ in dark at $\mathrm{pH}$ 7. The density profile in (b) was obtained along the straight line shown in (a) to prove the decrease in the electron intensity in the core as a consequence of the hollowing process. 
The $\mathrm{N}_{2}$ gas adsorption analysis confirmed the formation of void frameworks, as well as the value of BET surface area of the $\mathrm{FH}-\mathrm{SiO}_{2}$, which was more than double than that obtained for $\mathrm{F}_{-} \mathrm{SiO}_{2}$ (Table 1) and for conventional Stöber-like $\mathrm{SiO}_{2}$ nanoparticles (about $20 \mathrm{~m} / \mathrm{g}$ ). The $\mathrm{H} 1$ hysteresis loop of the isotherm for $\mathrm{FH}-\mathrm{SiO}_{2}$ and the steep decline around $\mathrm{p} / \mathrm{p}^{*}=0.5$ in desorption branch suggested the formation bottleneck mesopores in the nanoparticle surface (Figure 4) [38]. The estimated size of the interparticle gaps was slightly larger in $\mathrm{F}_{-} \mathrm{SiO}_{2}$ than in $\mathrm{FH}-\mathrm{SiO}_{2}$, where intraparticle pores reached values around $1.5 \mathrm{~nm}$. These could be responsible for an efficient water transport into the core, leading to the formation of inner voids.

Table 1. Textural properties of the ethanol-stabilized fluorescent silica nanoparticles $\left(\mathrm{F}-\mathrm{SiO}_{2}\right)$ and water-treated in dark for $5 \mathrm{~d}$ at $25^{\circ} \mathrm{C}\left(\mathrm{FH}-\mathrm{SiO}_{2}\right)$ obtained by $\mathrm{N}_{2}$ adsorption

\begin{tabular}{lllll}
\hline Sample & $\mathrm{S}_{\mathrm{BET}}{ }^{\dagger}\left(\mathrm{m}^{2} / \mathrm{g}\right)$ & $\mathrm{V}_{\mathrm{T}^{4}}\left(\mathrm{~cm}^{3} / \mathrm{g}\right)$ & $\mathrm{D}_{\mathrm{gap}}{ }^{\mathrm{s}}(\mathrm{nm})$ & $\mathrm{D}_{\mathrm{p}}^{\mathrm{s}}(\mathrm{nm})$ \\
\hline $\mathrm{F}_{-\mathrm{SiO}}$ & 129 & 0.17 & 58 & 1.2 \\
$\mathrm{FH}_{2} \mathrm{SiO}_{2}$ & 293 & 0.33 & 51 & 1.4
\end{tabular}

$\mathrm{S}_{\mathrm{вЕ}}$, Surface area calculated based on the BET model between $\mathrm{p} / \mathrm{p}^{*} 0.05$ and $0.3 ; \mathrm{V}_{\mathrm{t}}$, total pore volume at $\mathrm{p} / \mathrm{p}^{*}=0.99 ; \mathrm{D}_{\mathrm{gp}}$, interparticle gap and $\mathrm{D}_{\mathrm{p}}$, intraparticle mesopore diameter from NLDFT model at the adsorption branch of the isotherm. 

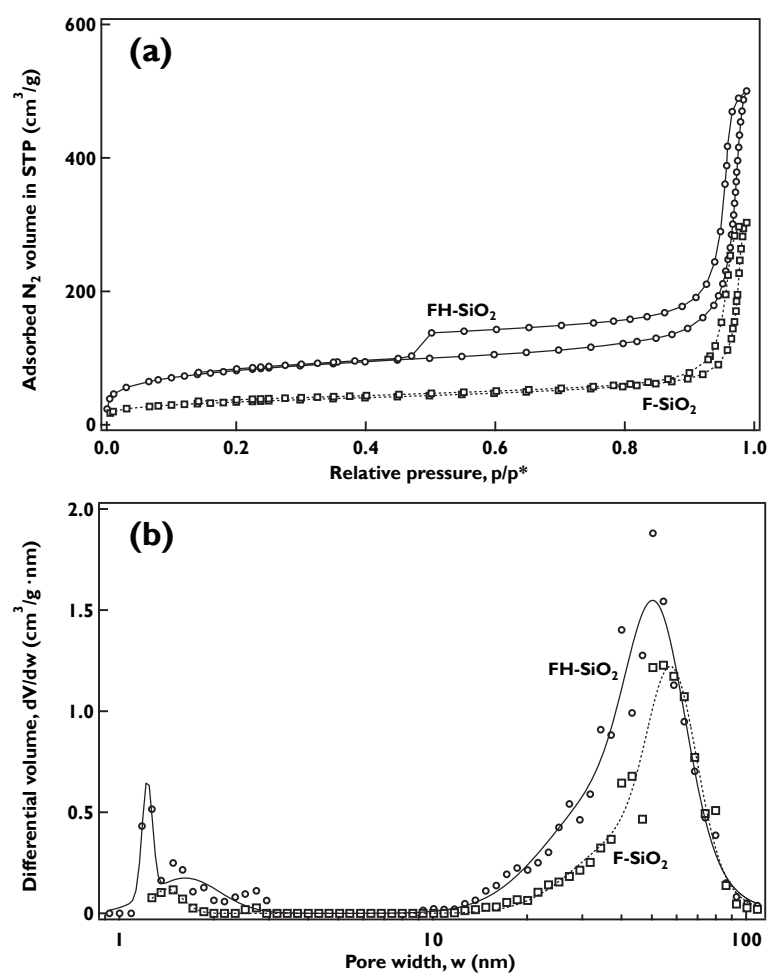

Figure 4. (a) $\mathrm{N}_{2}$ gas adsorption isotherms and (b) NLDFT pore size distributions of $\mathrm{F}-\mathrm{SiO}_{2}$ and $\mathrm{FH}-\mathrm{SiO}_{2}$ nanoparticles showing the increase in the adsorption volume after keeping $\mathrm{SiO}_{2}$ nanoparticles in water in dark for $5 \mathrm{~d}$ at $25^{\circ} \mathrm{C}$. The long hysteresis loop in $\mathrm{FH}-\mathrm{SiO}_{2}$ isotherm pointed out the formation of bottleneck mesopores, whereas the pore size distribution the formation of both inter and intraparticulate mesopores.

A series of experiments were carried out to determine the influence of the water in the formation of the hollow structure and further nanohybrid synthesis. For the sake of clarity, the unabridged experimental details and additional TEM images are given in the ESM file. It is worth noting that the $\mathrm{FH}-\mathrm{SiO}_{2}$ nanoparticles obtained after these tests displayed spherical shapes with uniform particle diameters around $60 \mathrm{~nm}$, whereas the sizes of internal cavities grew up to $40 \mathrm{~nm}$. Likewise, the effect of the solvent temperature on the hollow formation was explored under reflux to obtain $\mathrm{FH}-\mathrm{SiO}_{2}$ nanostructures similar to those from water treatment for $5 \mathrm{~d}$ at $25^{\circ} \mathrm{C}$, as well as it was observed at low temperature $\left(5 \mathrm{~d}, 4^{\circ} \mathrm{C}\right)$, which suggests that water diffusion is enabled at a wide range of solvent temperatures. The suspension $\mathrm{pH}$ exerts an effect in the synthesis of $\mathrm{FH}-\mathrm{SiO}_{2}$ nanoparticles, which show larger 
voids when increasing the medium $\mathrm{pH}$. The nanoparticles remain dense at $\mathrm{pH} 2$ after $30 \mathrm{~d}$ of immersion, while they are degraded and eventually dissolved at pH 9 (Figure 5). This suggests that the formation these $\mathrm{FH}-\mathrm{SiO}_{2}$ nanoparticles depended on the water diffusion and subsequent hydrolysis of alkoxysilanes in a silica-water interface. Such hydrolysis process has been recently reported as an activation-less mechanism [39], which suggests that the void formation occurs at low temperature and in absence of acid or alkaline catalysts. An increase in ionic strength of the $\mathrm{F}_{-} \mathrm{SiO}_{2}$ suspensions inhibits the formation of voids into nanoparticles, yet early stages of the hollowing process can be assumed when reaction is carried out under reflux. Finally, changes in the $\mathrm{H}_{2} \mathrm{O} / \mathrm{SiO}_{2}$ molar ratio (R) of the microemulsion for obtaining F$\mathrm{SiO}_{2}$ affect the synthesis of $\mathrm{FH}-\mathrm{SiO}_{2}$, showing that the formation of $\mathrm{FH}-\mathrm{SiO}_{2}$ is inhibited at high values of R (Figure 6). The increase of available water during microemulsion synthesis (i.e. at high $\mathrm{R}$ values) improved the silicate condensation and reduced the number of unreacted alkoxysilane species in the silica matrix [40]. This, in turn, reduced the formation of cavities in the nanoparticles during subsequent water treatment. Interestingly, when the synthesis of $\mathrm{F}-\mathrm{SiO}_{2}$ nanoparticles was performed through a modified Stöber procedure to incorporate both TEOS and FITC-APTES conjugate molecules as silica sources, the obtained nanoparticles showed a rough spherical shape with larger polydispersity and bimodal particle size distributions. The formation of cavities in the Stöber-like $\mathrm{F}_{-} \mathrm{SiO}_{2}$ nanoparticles was merely observed for large particles, which implied that the microemulsion route together with the introduction of the FITC-APTES favored an incomplete hydrolysis of the silica precursors during formation of siloxane framework. The increase in water availability during hydrolysis, such at high R or in Stöber synthesis, enabled the polycondensation of silanol groups and reduced the presence of unreacted fluorescein-linked organosilanes, therefore avoiding the formation of inner cavities. To further clarify the effect of the presence of organosilane clusters, fluorescein-free $\mathrm{SiO}_{2}$ nanoparticles were synthesized under similar microemulsion conditions and submitted to the above-described void formation process. Either replacing the FITC-APTES conjugate by APTES or using TEOS as the solely silicate precursor, the obtained $\mathrm{SiO}_{2}$ nanoparticles showed similar sizes and spherical shapes than those obtained for $\mathrm{F}-\mathrm{SiO}_{2}$. 

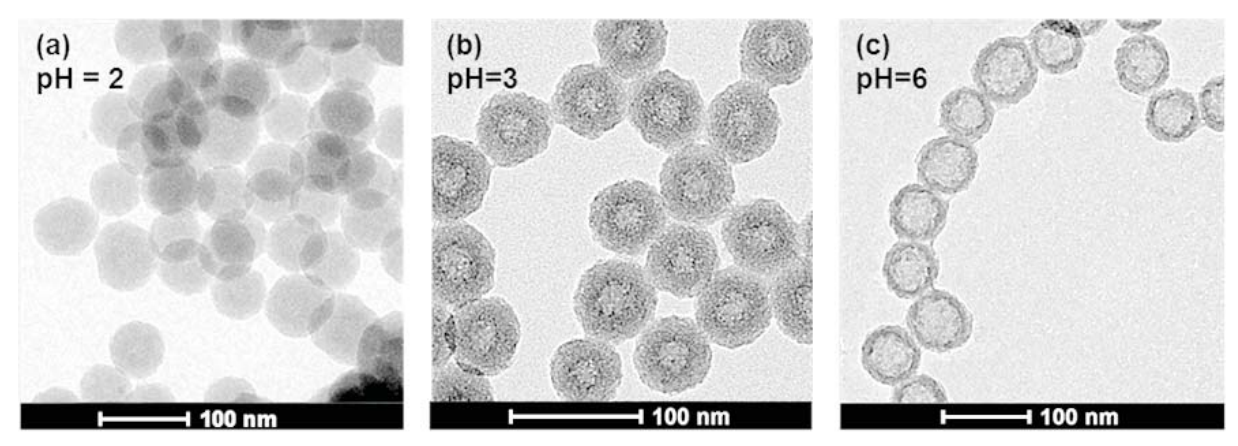

Figure 5. TEM images of the $\mathrm{F}-\mathrm{SiO}_{2}$ nanoparticles after immersion in water in dark at $25^{\circ} \mathrm{C}$ at pH 2 (a), pH 3 (b) and pH 6 (c). The formation of the inner cavities was boosted after increasing the $\mathrm{pH}$ of the ageing suspension.

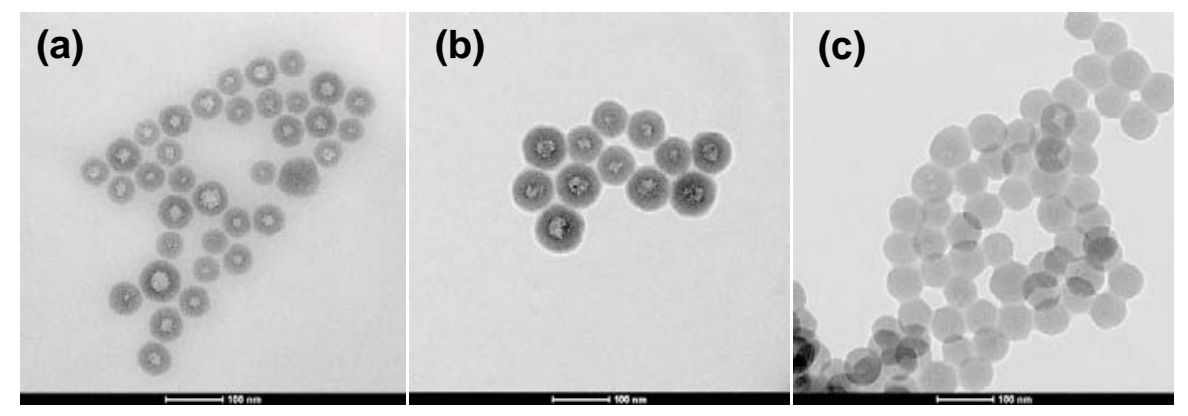

Figure 6. TEM images of the $\mathrm{F}-\mathrm{SiO}_{2}$ nanoparticles synthesized by the microemulsion method with $\mathrm{R}=\mathrm{H}_{2} \mathrm{O} / \mathrm{SiO}_{2}$ molar ratios of (a) 30 , (b) 40 and (c) 50 and further immersion in water in dark at $25^{\circ} \mathrm{C}$ for $5 \mathrm{~d}$. The formation of hollow nanostructures was reduced when increasing the accessibility of water to the synthesis gel in the microemulsion.

The UV-vis spectra of supernatant solutions after immersion of $\mathrm{F}_{-} \mathrm{SiO}_{2}$ nanoparticles show a broad absorption peak at $490 \mathrm{~nm}$, with a gradual increase in intensity with time (Figure 7). For comparison, spectra of the FITC dye molecule and FITC-APTES conjugate in water at $\mathrm{pH} 6$ were measured, showing the distinctive features of fluorescein dianion in polar solvents, i.e. a wide band at $490 \mathrm{~nm}$ and a minor band in the region of 350-400 nm [41]. This feature suggests that fluorescein-linked silicate clusters are being released upon formation of 
the voids. Furthermore, the 'H-NMR analysis of supernatant suspensions indicated the release of FITC-APTES clusters (see ESM).

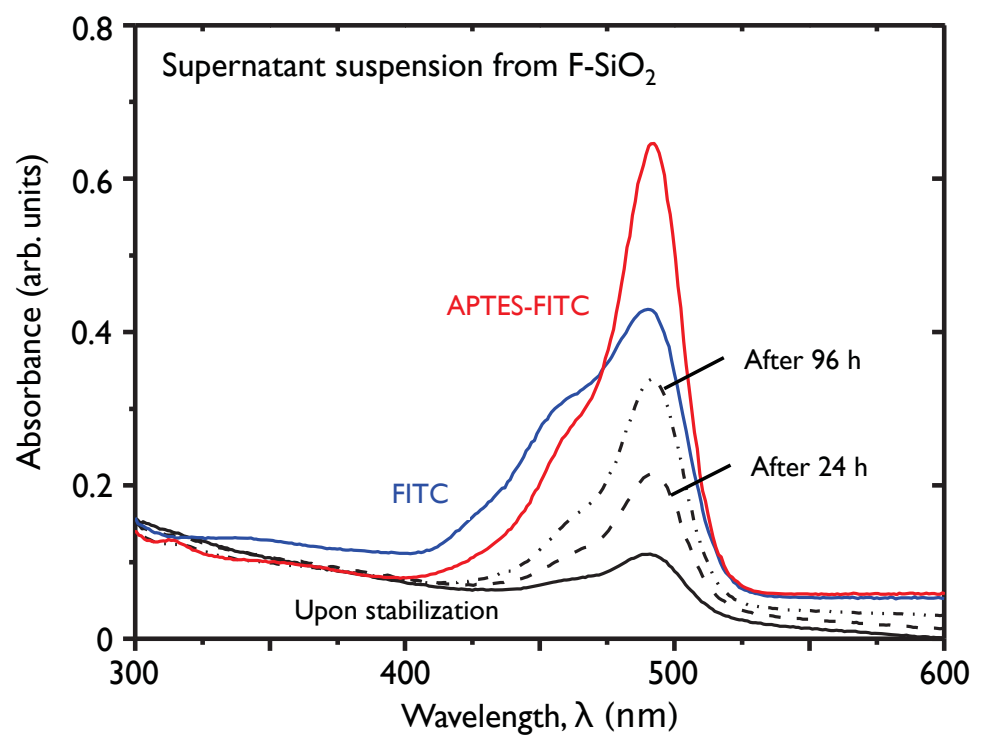

Figure 7. UV-vis spectra of supernatant obtained from water-stabilized $\mathrm{F}-\mathrm{SiO}_{2}$ suspensions upon stabilization (straight line), after $24 \mathrm{~h}$ (dashed line) and after $96 \mathrm{~h}$ (dotted line). The UVvis spectra of FITC (blue line) and APTES-FITC conjugate (red line) in water were included for comparison, pointing out the similarity of the supernatant spectra with that of the APTESFITC conjugate.

These results suggest that the microemulsion route together with the introduction of FITC-APTES conjugate caused an incomplete hydrolysis during the formation of the siloxane framework. The role of organic and silicate groups seems to be crucial in the formation of $\mathrm{FH}-\mathrm{SiO}_{2}$ nanoparticles as well the amount of water. The process is therefore driven by the initial growth of FITC-linked organoalkoxysilane nuclei that act as seeds for F-SiO nanoparticles. This suggests that $\left[\mathrm{O}_{3} \mathrm{Si}-\mathrm{R}-\mathrm{Fn}\right]$ units, with larger hydrophobicity, are mainly oriented inwards as silica nanoparticles mature within microemulsion droplets. A shell of fully polymerized silica is then formed while in the inner part the access of water to alkoxysilane groups is limited. The microemulsion breakage using anhydrous EtOH prevents further polymerization and dense $\mathrm{F}_{-} \mathrm{SiO}_{2}$ nanoparticles are produced. However, when $\mathrm{F}-\mathrm{SiO}_{2}$ nanoparticles are dispersed in aqueous media, the diffusion of water molecules to the inner 
core takes place through the surface mesopores, completing the hydrolysis of unreacted alkoxysilane groups releasing EtOH and fluorescein-linked silica clusters. Since the density of polymerized $\mathrm{SiO}_{2}$ is larger than that of $\left[\mathrm{O}_{3} \mathrm{Si}-\mathrm{R}-\mathrm{Fn}\right]$ units, the overall process leaves a void in the inner part of the nanoparticles, without affecting the outer silica shell.

Finally, porous shell and the inner core can be exploited for form metal nanohybrids. The inclusion of silver, gold and platinum nanoclusters could be achieved through immersion of $\mathrm{F}-\mathrm{SiO}_{2}$ nanoparticles in aqueous solutions of metal precursors and subsequent reduction with $\mathrm{NaBH}_{4}$. The STEM images show that the gold nanoparticles in the $\mathrm{Au} @ \mathrm{SiO}_{2}$ nanohybrids are present as disperse nanoparticles embedded in the silica matrix. On the other hand, both silver and platinum nanoparticles, generally with larger average sizes about $10 \mathrm{~nm}$, can be observed within $\mathrm{Ag} @ \mathrm{SiO}_{2}$ and $\mathrm{Pt} @ \mathrm{SiO}_{2}$ nanohybrids forming rattle-like structures (Figure 8). The observed morphological differences in the metal-silica nanohybrids can be attributed to changes in solvent conditions during metal inclusion and reduction in water. 

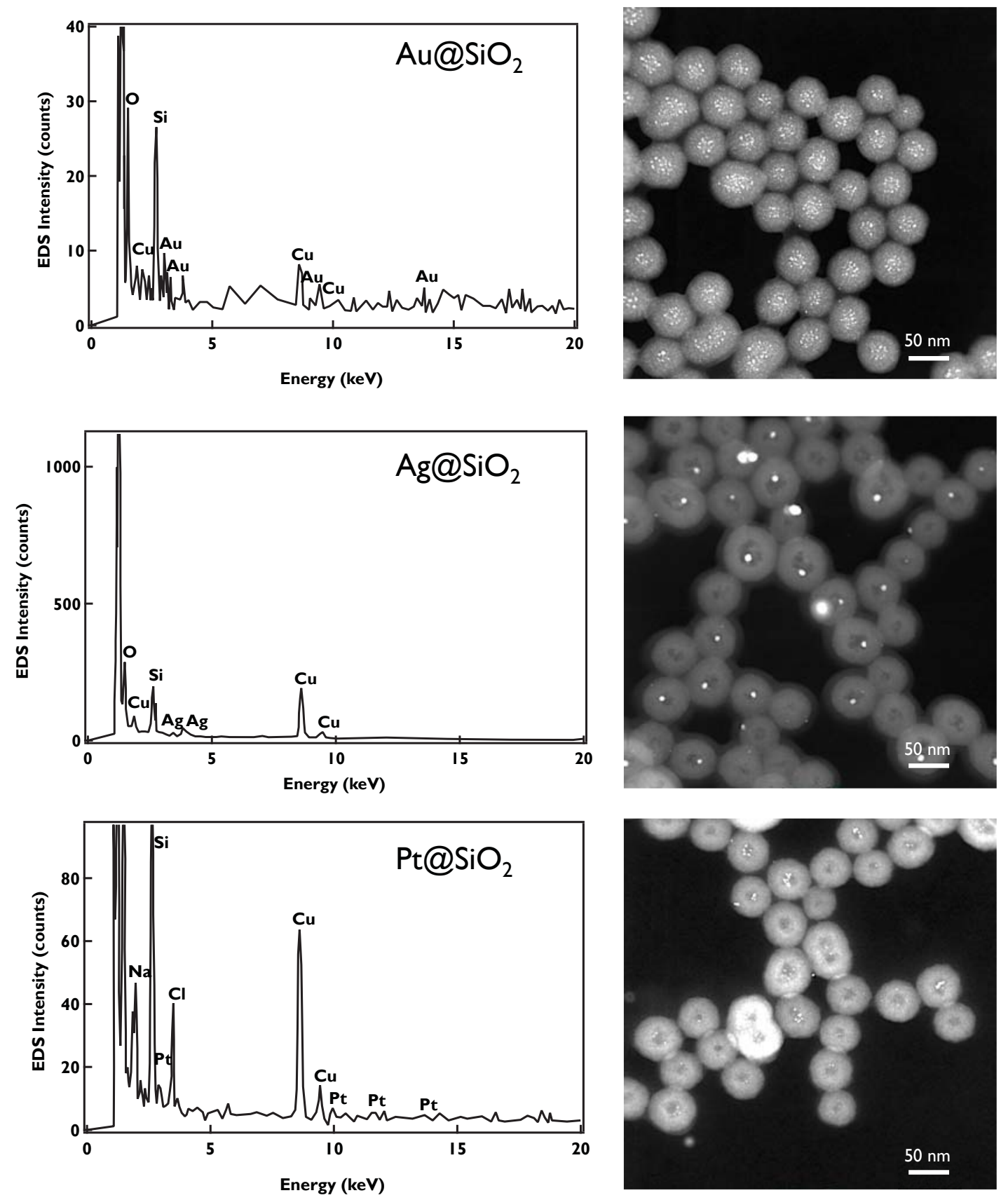

Figure 8. STEM-EDS spectra of $\mathrm{Au} @ \mathrm{FH}-\mathrm{SiO}_{2}, \mathrm{Ag} @ \mathrm{FH}-\mathrm{SiO}_{2}$ and $\mathrm{Pt} @ \mathrm{FH}-\mathrm{SiO}_{2}$ nanohybrids synthesized by immersion of $\mathrm{F}-\mathrm{SiO}_{2}$ in $1-\mathrm{mM}$ aqueous solutions of $\mathrm{AgNO}_{3}, \mathrm{HAuCl}_{4}$ and $\mathrm{H}_{2} \mathrm{PtCl}_{6}$ at $25^{\circ} \mathrm{C}$ for $5 \mathrm{~d}$ in dark. The high-angle annular dark field (HAADF) STEM tomography images of analogous nanohybrids showed the formation of the hollow structure and the inclusion of metal nanoparticles. 
The confinement of the metal in the inner regions of the particle was confirmed by XPS analysis. Results showed that the atomic concentration of metals in the surface of $\mathrm{M} @ \mathrm{SiO}_{2}$ nanohybrids was very low, especially for $\mathrm{Au}$ and $\mathrm{Pt}$, since the intensity of $\mathrm{Au} 3 \mathrm{p}$, and Pt3d signals was under $0.1 \%$ relative to the reference C1s peak (Figure 9a). However, when etching the nanomaterial surface using $\mathrm{Ar}^{+}$ion beam milling the signal intensity of the metal atoms increased with the etching time; suggesting that metals at the inner core are progressively exposed. Indeed, the relative metal-to-silicon (M/Si) signal intensity is nearly zero at the surface of $\mathrm{Au} @ \mathrm{SiO}_{2}$ and $\mathrm{Pt} @ \mathrm{SiO}_{2}$ nanohybrids whereas for $\mathrm{Ag} @ \mathrm{SiO}_{2}$ is about 2.5 times higher (Figure 9b). This indicates that some silver nanoparticles are present at the surface of $\mathrm{SiO}_{2}$, although they represent a small fraction of the total. Finally, the $\mathrm{M} @ \mathrm{SiO}_{2}$ nanohybrids show fluorescent emission around $516 \mathrm{~nm}$, which confirms the dual functionality (fluorescent + metallic) of these nanohybrid structures and suggest applications in multiple fields. Prospective uses of these nanomaterials in nanomedicine and photocatalysis are currently under research and results will be reported in future publications. 

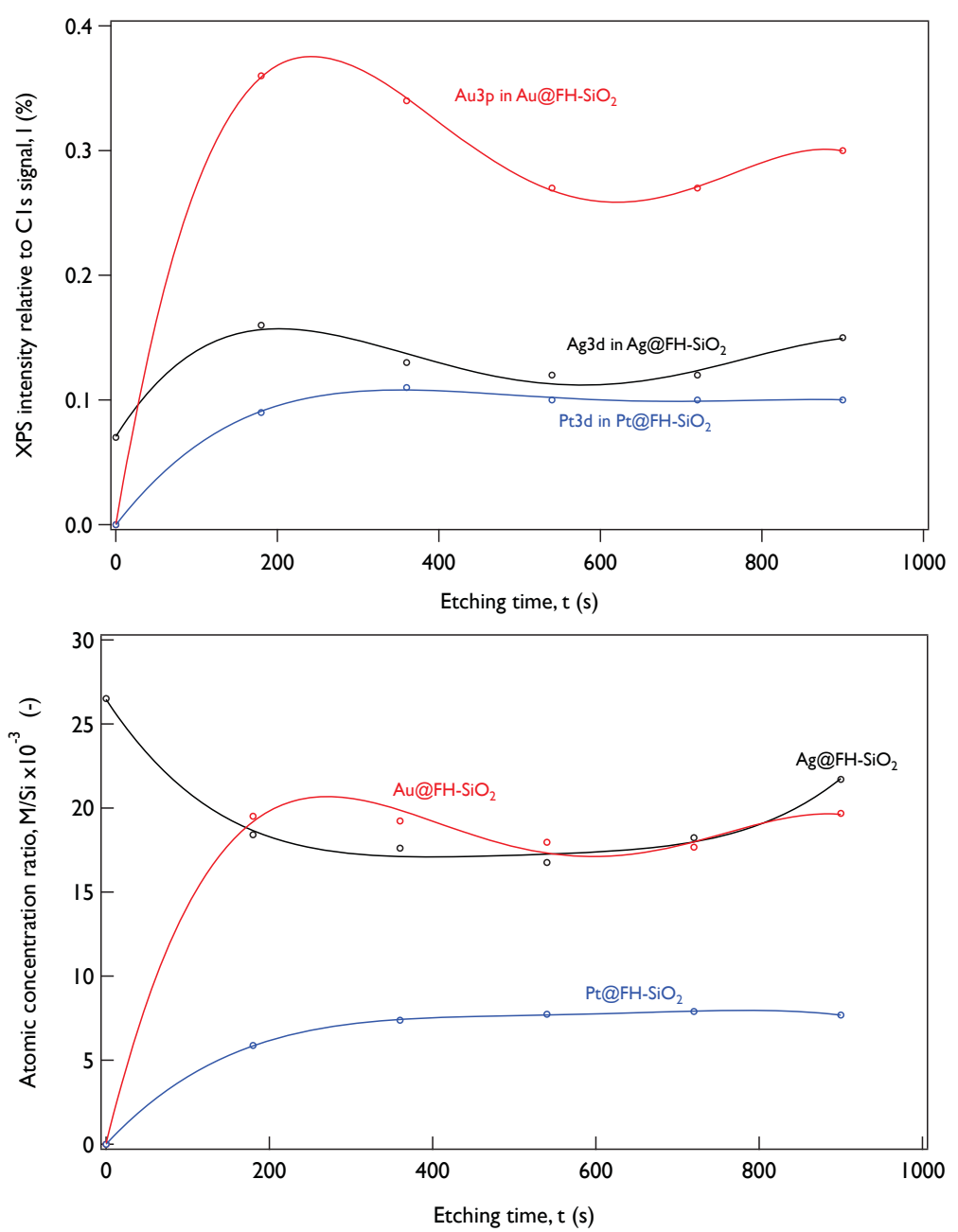

Figure 9. Evolution of the relative intensity of XPS Au3d, Ag3p and Pt3d to C1s signal at $286 \mathrm{eV}$ as a function of the etching time of $\mathrm{Ar}$ for $\mathrm{Au} @ \mathrm{FH}-\mathrm{SiO}_{2}, \mathrm{Ag} @ \mathrm{FH}-\mathrm{SiO}_{2}$ and $\mathrm{Pt} @ \mathrm{FH}-$ $\mathrm{SiO}_{2}$ nanoparticles.

\section{CONCLUSIONS}

Metal-containing silica nanohybrids and hollow silica structures can be produced using a simple two-stage process. The procedure allows the formation of singular nanostructures such as metal-filled $\mathrm{Au} @ \mathrm{SiO}_{2}$ nanoparticles and $\mathrm{Ag} @ \mathrm{SiO}_{2}$ or $\mathrm{Pt} @ \mathrm{SiO}_{2}$ nanorattles. The synthesis of these nanohybrids is possible thanks to a process that creates inner voids starting from microemulsion-assisted synthesis of fluorescent $\mathrm{F}-\mathrm{SiO}_{2}$ nanoparticles followed by further reaction in water. The formation of these inner cavities in silica nanoparticles can be 
effectively controlled by modification of the solvent thermal and $\mathrm{pH}$ conditions as well as the degree of polymerization of the silica structure before the aqueous treatment. The silica-metal nanohybrids formed have potential application in fields such as catalysis, optics or nanomedicine.

\section{ACKNOWLEDGEMENTS}

Financial support from the Government of Aragon and European Social Fund were gratefully acknowledged. Funding from the European Union $7^{\text {th }}$ Framework Programme under the project "NanoValid, Development of reference methods for hazard identification, risk assessment and LCA of engineered nanomaterials" (Grant Agreement \#263147). F.B. thanks financial support from the Ministry of Economy and Competitiveness of Spain (MINECO) 'Ramón y Cajal' Programme (Contract RYC-2011-07641). M.P.L. thanks financial support from the MINECO 'Juan de la Cierva' Programme (Contract JCI-2012-13421). Finally, authors acknowledged the helpful discussions with Prof. Dr. E. P. Urriolabeitia of the Instituto de Ciencia de Materiales de Aragón (ICMA-CSIC) on 'H-NMR spectroscopy and the help of Dr. N. Navascués of the Instituto de Nanociencia de Aragón (INA) in the TEM and STEM analysis.

\section{ELECTRONIC SUPPLEMENTARY MATERIAL}

Detailed experimental procedures and methods, details on the $\mathrm{N}_{2}$ adsorption analysis and the NLDFT model used for estimating the porosity, additional TEM and HRTEM images of $\mathrm{FH}-\mathrm{SiO}_{2}$ nanoparticles obtained under different conditions and 'H-NMR spectra of supernatant suspensions after immersion of $\mathrm{F}-\mathrm{SiO}_{2}$ in deuterated methanol are available in the online version of this article.

\section{REFERENCES}


[1] Roco, M. C. The long view of nanotechnology development: the National Nanotechnology Initiative at 10 years. J. Nanopart. Res. 2011, 13, 427-445.

[2] Ozin, G. A. Spin of a Nanotech Spin-Off. Adv. Eng. Mater. 2013, 15, 8-18.

[3] Cao, G. Nanostructures and Nanomaterials. Synthesis, Properties and Applications; Imperial College Press: London, 2004.

[4] Sebastian, V.; Arruebo, M.; Santamaria, J. Reaction engineering strategies for the production of inorganic nanomaterials. Small 2014, 10, 835-853.

[5] He, M.; Qiu, F.; Lin, Z. Toward high-performance organic-inorganic hybrid solar cells: bringing conjugated polymers and inorganic nanocrystals in close contact. J. Phys. Chem. Lett. 2013, 4, 1788-1796.

[6] Ramos, J.; Hidalgo-Alvarez, R.; Forcada, J. Facile synthesis of thermoresponsive nanohybrids. Soft Matter 2013, 9, 8415-8419.

[7] Beltram, A.; Melchionna, M.; Montini, T.; Nasi, L.; Gorte, R. J.; Prato, M.; Fornasiero, P. Improved activity and stability of $\mathrm{Pd} @ \mathrm{CeO}_{2}$ core-shell catalysts hybridized with multi-walled carbon nanotubes in the water gas shift reaction. Catal. Today. 2015, 253, 142-148.

[8] Lei, P.; Wang, F.; Zhang, S.; Ding, Y.; Zhao, J.; Yang, M. Conjugation-grafted-TiO nanohybrid for high photocatalytic efficiency under visible light. ACS Appl. Mater. Int. 2014, 6, 2370-2376.

[9] Maji, S. K.; Mandal, A. K.; Nguyen, K. T.; Borah, P.; Zhao, Y. Cancer cell detection and therapeutics using peroxidase-active nanohybrid of gold nanoparticle-loaded mesoporous silica-coated graphene. ACS Appl. Mater. Int. 2015, 7, 9807-9816.

[10] Sui, N.; Monnier, V.; Salvia, M.-V.; Chevolot, Y.; Souteyrand, E. Magnetic and optical properties of $\mathrm{Ag} @ \mathrm{SiO}_{2}-\mathrm{FITC}_{-} \mathrm{Fe}_{3} \mathrm{O}_{4}$ hybrid nanoparticles. Mater. Sci. Eng. B 2014, 182, 92-95.

[11] Islam, M. M.; Aboutalebi, S. H.; Cardillo, D.; Liu, H. K.; Konstantinov, K.; Dou, S. X. Self-assembled multifunctional hybrids: toward developing high-performance graphene-based architectures for energy storage devices. ACS Cent. Sci. 2015, 1, 206216. 
[12] Benson, O. Assembly of hybrid photonic architectures from nanophotonic constituents. Nature 2011, 480, 193-199.

[13] Vitorge, E.; Szenknect, S.; Martins, J. M.-F.: Barthes, V.; Gaudet, J.-P. Comparison of three labeled silica nanoparticles used as tracers in transport experiments in porous media. Part II: Transport experiments and modeling. Environ. Poll. 2014, 184, 613-619.

[14] Jin, Y. H.; Li, A. Z.; Hazelton, S. G.; Liang, S.; John, C. L.; Selid, P. D.; Pierce, D. T.; Zhao, J. X. Amorphous silica nanohybrids: Synthesis, properties and applications. Coord. Chem. Rev. 2009, 253, 2998-3014.

[15] Clemente, A.; Moreno, N.; Lobera, M. P.; Balas, F.; Santamaria, J. Fluorescently labelled $\mathrm{SiO}_{2}$ nanoparticles as tracers in natural waters. Dependence of detection limits with environmental conditions. Environ. Sci. Nano. 2016, 3, 631-637.

[16] Wang, Z.; Wu, L.; Chen, M.; Zhou, S. Facile synthesis of superparamagnetic fluorescent $\mathrm{Fe}_{3} \mathrm{O}_{4} / \mathrm{ZnS}$ hollow nanospheres. J. Am. Chem. Soc. 2009, 131, 11276-11277.

[17] Wu, L.; Guo, Q.-S.; Liu, Y.-Q.; Sun, Q.-J. Fluorescence resonance energy transferbased ratiometric fluorescent probe for detection of $\mathrm{Zn}^{2+}$ using a dual-emission silicacoated quantum dots mixture. Anal. Chem. 2015, 87, 5318-5323.

[18] Sreejith, S.; Joseph, J.; Nguyen, K. T.; Murukeshan, V. M.; Lye, S. W .; Zhao, Y. Graphene oxide wrapping of gold-silica core-shell nanohybrids for photoacoustic signal generation and bimodal imaging. ChemNanoMat 2015, 1, 39-45.

[19] Pineda, A.; Gomez, L.; Balu, A. M.; Sebastian, V.; Ojeda, M.; Arruebo, M.; Romero, A. A.; Santamaria, J.; Luque, R. Laser-driven heterogeneous catalysis: Efficient amide formation catalysed by $\mathrm{Au} / \mathrm{SiO}_{2}$ systems. Green Chem. 2013, 15, 2043-2049.

[20] Gomez, L.; Sebastian, V.; Arruebo, M.; Santamaria, J.; Cronin, S. B. Plasmon-enhanced photocatalytic water purification. Phys. Chem. Chem. Phys. 2014, 16, 15111-15116.

[21] Yang, S.; Chen, D.; Li, N.; Xu, Q.; Li, H.; Gu, F.; Xie, J.; Lu, J. Hollow mesoporous silica nanocarriers with multifunctional capping agents for in vivo cancer imaging and therapy. Small 2016, 12, 360-370. 
[22] Yang, D.; Wang, Y.; Wang, Y.; Li, Z.; Li, H. Luminescence enhancement after adding organic salts to nanohybrid under aqueous condition. ACS Appl. Mater. Int. 2015, 7 , 2097-2103.

[23] Roca, A. G.; Carmona, D.; Miguel-Sancho, N.; Bomati-Miguel, O.; Balas, F.; Piquer, C.; Santamaria, J. Surface functionalization for tailoring the aggregation and magnetic behavior of silica-coated iron oxide nanostructures. Nanotechnology 2012, 23, 155603.

[24] Praneetha, S.; Murugan, A. V. Development of sustainable rapid microwave assisted process for extracting nanoporous Si from earth abundant agricultural residues and their carbon-based nanohybrids for lithium energy storage. ACS Sust. Chem. Eng. 2015, 3, 224-236.

[25] Li, Y.; Bastakoti, B. P.; Imura, M.; Tang, J.; Aldalbahi, A.; Torad, N. L.; Yamauchi, Y. Dual Soft-Template System Based on Colloidal Chemistry for the Synthesis of Hollow Mesoporous Silica Nanoparticles. Chem. Eur. J. 2015, 21, 6375-6380.

[26] Wang, Y.; Su, X.; Ding, P.; Lu, S.; Yu, H. Shape-Controlled Synthesis of Hollow Silica Colloids. Langmuir 2013, 29, 11575-11581.

[27] Singh, L. P.; Bhattacharyya, S. K.; Kumar, R.; Mishra, G.; Sharma, U.; Singh, G.; Ahalawat, S. Sol-gel processing of silica nanoparticles and their applications. Adv. Coll. Int. Sci. 2014, 214, 17-37.

[28] Chen, M.; Wu, L.; Zhou, S.; You, B. A method for the fabrication of monodisperse hollow silica spheres. Adv. Mater. 2006, 18, 801-806.

[29] Hu, J.; Chen, M.; Fang, X.; Wu, L. Fabrication and application of inorganic hollow spheres. Chem. Soc. Rev. 2011, 40, 5472-5491.

[30] Yec, C. C.; Zeng, H. C. Synthesis of complex nanomaterials via Ostwald ripening. J. Mater. Chem. A 2014, 2, 4843-4851.

[31] Mahon, E.; Hristov, D. R.; Dawson, K. A. Stabilising fluorescent silica nanoparticles against dissolution effects for biological studies. Chem. Commun. 2012, 48, 7970-7972.

[32] Lismont, M.; Paez, C. A.; Dreesen, L. A one-step short time synthesis of Ag@ $\mathrm{SiO}_{2}$ core-shell nanoparticles. J. Coll. Int. Sci. 2015, 447, 40-49. 
[33] Sharma, P.; Bengtsson, N. E.; Walter, G. A.; Sohn, H.-B.; Zhou, G.; Iwakuma, N.; Zeng, H.; Grobmyer, S. R.; Scott, E. W.; Moudgil, B. M. Gadolinium-doped silica nanoparticles encapsulating indocyanine green for near infrared and magnetic resonance imaging. Small 2012, 8, 2856-2868.

[34] Lee, J.; Kim, S. M.; Lee, I. S. Functionalization of hollow nanoparticles for nanoreactor applications. Nano Today 2014, 9, 631-667.

[35] Santra, S.; Yang, H.; Dutta, D.; Stanley, J. T.; Holloway, P. H.; Tan, W.; Moudgil, B. M.; Mericle. R. A. TAT conjugated, FITC doped silica nanoparticles for bioimaging applications. Chem. Commun. 2004, 2810-2811.

[36] Kirillov, S. A. Surface area and pore volume of a system of particles as a function of their size and packing. Micropor. Mesopor. Mater. 2009, 122, 234-239.

[37] Weyland, M. Electron tomography of catalysts. Top. Catal. 2002, 21, 175-183.

[38] Gregg, S. J.; Sing, K. S. W. Adsorption Surface Area and Porosity; Academic Press: London, 1967.

[39] Lowe, B. M.; Skylaris, C.-K.; Green, N. G. Acid-base dissociation mechanisms and energetics at the silica-water interface: An activationless process. J. Coll. Int. Sci. 2015, $451,231-244$

[40] Brinker, C. J.; Scherer, G. W. Sol-gel science, the physics and chemistry of sol-gel processing; Academic Press: New York, 1990.

[41] Guo, Y.; Davidson, R. A.; Peck, K. A.; Guo, T. Encapsulation of multiple large spherical silica nanoparticles in hollow spherical silica shells. J. Coll. Int. Sci. 2015, $445,112-118$. 